\title{
Etika Uang, Religiusitas, dan Penggelapan Pajak (Studi Kasus Wajib Pajak Orang Pribadi di Kabupaten Gunungkidul)
}

\author{
Faishal Prahatma Ganinda $^{1 *}$, Kahfi Fikrianoor ${ }^{2}$, Agung Dwi Nugroho ${ }^{3}$, Amir Hidayatulloh ${ }^{4}$ \\ 1,2,3,4 Universitas Ahmad Dahlan, Yogyakarta, Indonesia \\ 11 prahatmag@gmail.com, ${ }^{2}$ kahfifikri@gmail.com, ${ }^{3}$ agungdwinugroho846@ gmail.com, ${ }^{4}$ amir.hidayatulloh@ act.uad.ac.id \\ * corresponding author
}

\section{ARTICLE INFO}

\section{Article history}

Received 2020-02-14

Revised 2020-05-05

Accepted 2020-06-25

Keywords

Money Ethic, Religiosity, Tax Evasion.

\begin{abstract}
ABSTRA CT
This research aims to determine the role of religiosity on the influence of money ethics on tax evasion. The population in this research is individual taxpayers in the Special Region of Yogyakarta. The sample in this research is an individual taxpayer in Gunungkidul district. Sampling in this research uses purposive sampling, with criteria (1) individual taxpayers who have a NPWP, (2) individual taxpayers who carry out business activities or free work. The research data was obtained by distributing questionnaires directly to respondents who met the criteria. This research obtained 42 respondents. Data analysis techniques in this research used Partial Least Square with the help of WarpPLS. This research results show that money ethics influences tax avoidance. However, tax evasion is not influenced by religiosity. This research also proves that the variable of religiosity moderates the influence between money ethics and tax evasion.
\end{abstract}

\section{PENDAHULUAN}

Pajak merupakan sumber terbesar pendapatan negara. Pajak memiliki dua fungsi yaitu fungsi budgetair dan fungsi regulerend. Fungsi budgetair yaitu fungsi yang bertujuan untuk meningkatkan kas negara sebanyak-banyaknya guna memenuhi pembiayaan pembangunan dan pengeluaran yang dilakukan oleh pemerintah pusat maupun pemerimtah daerah (Mardiasmo, 2009). Sedangkan, fungsi regulerend memiliki tujuan untuk mengatur dan melaksanakan kebijakan pemerintah dalam bidang ekonomi dan sosial (Mardiasmo, 2009). Fungsi-fungsi tersebut digunakan untuk tujuan mengatur dan memenuhi target penerimaan pajak yang telah ditetapkan oleh pemerintah. Namun berdasarkan (Inggit, 2019) mengungkapkan bahwa realisasi penerimaan pajak pada tahun 2018 mencapai Rp1.315,9 triliun atau hanya 92 persen realisasi dari target APBN 2018 yaitu sebesar Rp1.414 triliun, artinya realisasi penerimaan pajak pada tahun tersebut tidak mencapai target. Tidak tercapaianya target penerimaan pajak tersebut disebabkan adanya wajib pajak yang meminimalkan pajaknya dengan berbagai cara, salah satunya yaitu tax evasion.

Tax evasion merupakan kegiatan penggelapan pajak dengan mengecilkan atau meminimalkan jumlah pajak yang terutang secara illegal (Rosianti \& Mangoting, 2014). Para wajib pajak berusaha untuk meminimalkan beban pajak yang harus dibayarkan secara illegal. Hal ini dilakukan wajib pajak karena alasan para wajib pajak melakukan tax evasion dapat dipengaruhi oleh money ethic atau etika uang yang menurut wajib pajak uang merupakan segalanya (Sloan, 2002).

Alasan lain yang mendukung adalah adanya money ethic, yaitu ketika uang merupakan prioritas yang utama dalam diri seseorang, maka mereka akan merasa bahwa melakukan tax evasion merupakan tindakan yang dapat diterima (Lau, Choe \& Tan, 2013). Money ethic memiliki hubungan secara langsung dengan tindakan yang tidak etis. Hal ini berarti semakin seseorang memprioritaskan uang sebagai sesuatu yang sangat penting, maka orang tersebut lebih cenderung untuk melakukan penggelapan pajak (tax evasion) yang tidak etis daripada seseorang yang tidak terlalu memprioritaskan uang sebagai sesuatu yang sangat penting (Tang, 2002)

Keyakinan seseorang terhadap agama yang dianut dapat memoderasi hubungan antara etika uang terhadap penggelapan pajak. Perilaku etis dan tidak etisnya perbuatan seseorang secara tidak langsung didasari oleh keyakinan yang tertanam dalam dirinya. Menurut (Hutami, 2012), tindakan penggelapan 
pajak merupakan tindakan yang dilarang oleh agama. Penelitian lain juga mengungkapkan bahwa variabel religiusitas memiliki pengaruh yang sangat kuat sebagai pencegah tindakan penggelapan pajak (McKerchar, 2013). Dari uraian sebelumnya, tujuan penelitian ini adalah untuk mengetahui peran religiusitas pada pengaruh etika pada penggelapan pajak.

\section{METODE PENELITIAN}

Penelitian ini merupakan penelitian kuantitatif. Populasi dalam penelitian ini adalah wajib pajak orang pribadi di Daerah Istimewa Yogyakarta. Sampel dalam penelitian ini adalah wajib pajak orang pribadi di daerah Gunungkidul. Teknik pengambilan sampel dalam penelitian ini menggunakan purposive sampling dengan kriteria (1) wajib pajak orang pribadi yang memiliki NPWP, (2) wajib pajak orang pribadi yang melakukan kegiatan usaha atau pekerjaan bebas. Data dalam penelitian ini diperoleh dengan menyebarkan kuesioner secara langsung kepada responden yang memenuhi kriteria. Teknik analisis data dalam penelitian ini menggunakan Partial Least Square dengan bantuan WarpPLS. Definisi operasional dan pengukuran variabel dalam penelitian ini diasjikan dalam tabel I.

Tabel 1. Definisi Operasional dan Pengukuran Variabel

\begin{tabular}{|c|c|c|c|c|}
\hline Keterangan & Definisi Operasional & Referensi & Pengukuran & Referensi \\
\hline Etika Uang & $\begin{array}{l}\text { Perbedaan skala prioritas } \\
\text { tiap individu dalam } \\
\text { menggunakan uang } \\
\text { untuk kebutuhan sehari- } \\
\text { hari }\end{array}$ & $\begin{array}{l}\text { (Hafizhah, } \\
\text { 2016) }\end{array}$ & $\begin{array}{l}\text { Delapan item } \\
\text { pertanyaan dan } \\
\text { diukur dengan skala } \\
\text { likert lima point }\end{array}$ & (Azjen, 1977) \\
\hline $\begin{array}{l}\text { Penggelapan } \\
\text { Pajak }\end{array}$ & $\begin{array}{l}\text { Suatu usaha yang } \\
\text { dilakukan oleh wajib } \\
\text { pajak untuk meringankan } \\
\text { beban pajak secara ilegal } \\
\text { dan melanggar undang- } \\
\text { undang, serta } \\
\text { mengabaikan ketentuan } \\
\text { formal perpajakan yang } \\
\text { menjadi kewajibannya. }\end{array}$ & $\begin{array}{l}\text { (Mardiasmo, } \\
\text { 2009) }\end{array}$ & $\begin{array}{l}\text { Delapan item } \\
\text { pertanyaan dan } \\
\text { diukur dengan skala } \\
\text { likert lima point }\end{array}$ & (Azjen, 1977) \\
\hline Religiusitas & $\begin{array}{l}\text { Sebuah kepercayaan } \\
\text { kepada tuhan dan } \\
\text { mengikuti aturan-aturan } \\
\text { serta prinsip-prinsip yang } \\
\text { telah ditetapkan oleh } \\
\text { tuhan }\end{array}$ & $\begin{array}{l}\text { (McDaniel, } \\
\text { S.W. and } \\
\text { Burnett, 1990) }\end{array}$ & $\begin{array}{l}\text { Enam item } \\
\text { pertanyaan dan } \\
\text { diukur dengan skala } \\
\text { likert lima point }\end{array}$ & $\begin{array}{l}\text { Mehrad \& } \\
\text { Mohammadi, } \\
\text { 2017) }\end{array}$ \\
\hline
\end{tabular}

Penelitian ini melakukan pilot study terlebih dahulu sebelum melakukajn pengujian hipotesis. Tujuan dilakukannya pilot study yaitu untuk mengetahui variabel dalam kuesioner telah memenuhi uji validitas dan uji reiabilitas, hasilnya variabel kuesioner dalam penelitian ini telah memenuhi uji validitas dan uji reliabilitas. Alat analisis data dalam penelitian ini menggunakan bantuan warpPLS sebagai persamaan struktural berbasis varians yang secara simultan dapat melakukan pengujian model pengukuran dan pengujian model struktural (Nugroho \& Masduqi, 2014)

\section{HASIL DAN PEMBAHASAN}

Responden dalam penelitian ini berjumlah 42 responden. Responden berjenis kelamin laki-laki berjumlah 26 responden, sedangkan 16 responen berjenis kelamin perempuan. Usia responden dalam penelitian ini didominasi oleh responden dengan rentang usia 35-40 tahun, yaitu sebanyak 15 responden. Responden dalam penelitian ini didominasi oleh responden yang berpendidikan terakhir pada jenjang SMA, yaitu sebanyak 18 responden. 
Penelitian ini melakukan pengujian model pungukuran untuk menguji validitas konstruk dan reliabilitas instrumen (Tentama, 2019). Uji validitas dalam penelitian ini yaitu uji validitas konvergen dan uji validitas diskriminan. Uji validitas konvergen adalah uji validitas terkait dengan pengukuran yang timbul sangat tinggi dari konstruk. Sedangkan uji validitas diskriminan adalah uji validitas terkait dengan pengukuran yang tidak berkorelasi tinggi atau rendah (Hartono \& Abdillah, 2014) Hasil pengujian validitas dapat dilihat pada tabel 2 berikut.

Tabel 2. Hasil Uji Validitas

\begin{tabular}{|l|c|c|c|c|}
\hline & Money Ethic & Tax Evasion & Religiusitas & AVE \\
\hline ME 1 & $(0.545)$ & & \\
\hline ME 2 & $(0.532)$ & & \\
\hline ME 3 & $(0.663)$ & & \\
\hline ME 4 & $(0.812)$ & & \\
\hline ME 5 & $(0.771)$ & & \\
\hline ME 6 & $(0.767)$ & & \\
\hline ME 7 & $(0.775)$ & & $(0.733)$ \\
\hline ME 8 & $(0.674)$ & $(0.774)$ & $(0.714)$ \\
\hline TE 1 & & $(0.595)$ & $(0.647)$ \\
\hline TE 2 & & $(0.606)$ & \\
\hline TE 3 & & $(0.619)$ & \\
\hline TE 4 & & $(0.811)$ & \\
\hline TE 5 & & $(0.744)$ & \\
\hline TE 6 & & & \\
\hline TE 7 & & & \\
\hline TE 8 & & & \\
\hline R 1 & & & \\
\hline R 2 & & & \\
\hline R 3 & & & \\
\hline R 4 & & & \\
\hline R 5 & & & \\
\hline R 6 & & & \\
\hline
\end{tabular}

Sumber: data primer diolah (2019)

Hasil pengujian validitas yang disajikan pada tabel 2 menunjukan bahwa semua item pertanyaan kuesioner valid. Hal ini dapat dilihat dari nilai loading yang lebih besar dari 0,5 dan nilai AVE yang lebih besar dari 0,5 (Imam, G., \& Latan, 2014). Penelitian ini juga melakukan uji reliabilitas untuk mengukur konsistensi internal alat ukur. Parameter yang digunakan untuk uji reliabilitas ini yaitu menggunakan composite reliability dengan nilai rule of thumb lebih dari 0,7. Hasil uji reliabilitas dalam penelitian ini disajikan pada tabel 3 berikut ini. 
Tabel 3. Hasil Uji Reliabilitas

\begin{tabular}{|c|c|c|c|}
\hline \multirow{2}{*}{ Composite Reliability } & ME & TE & $\mathrm{R}$ \\
\cline { 2 - 4 } & 0,910 & 0,907 & 0,877 \\
\hline
\end{tabular}

Sumber: data primer, diolah (2019)

Tabel 3 menunjukan hasil uji reliabilitas. Hasil uji relibilitas dalam penelitian ini menunjukan angka diatas 0,5 yang berarti bahwa penelitian ini memenuhi uji reliabilitas (Imam, G., \& Latan, 2014). Tahap selanjutnya yaitu pengujian model struktural, pengujian struktural dalam penelitian ini dilakukan dengan menggunakan $R$-square dan nilai koefisien path atau $t$-value pada tiap path. Hasil uji model struktural dalam penelitian ini disajikan dalam gambar 1 berikut.

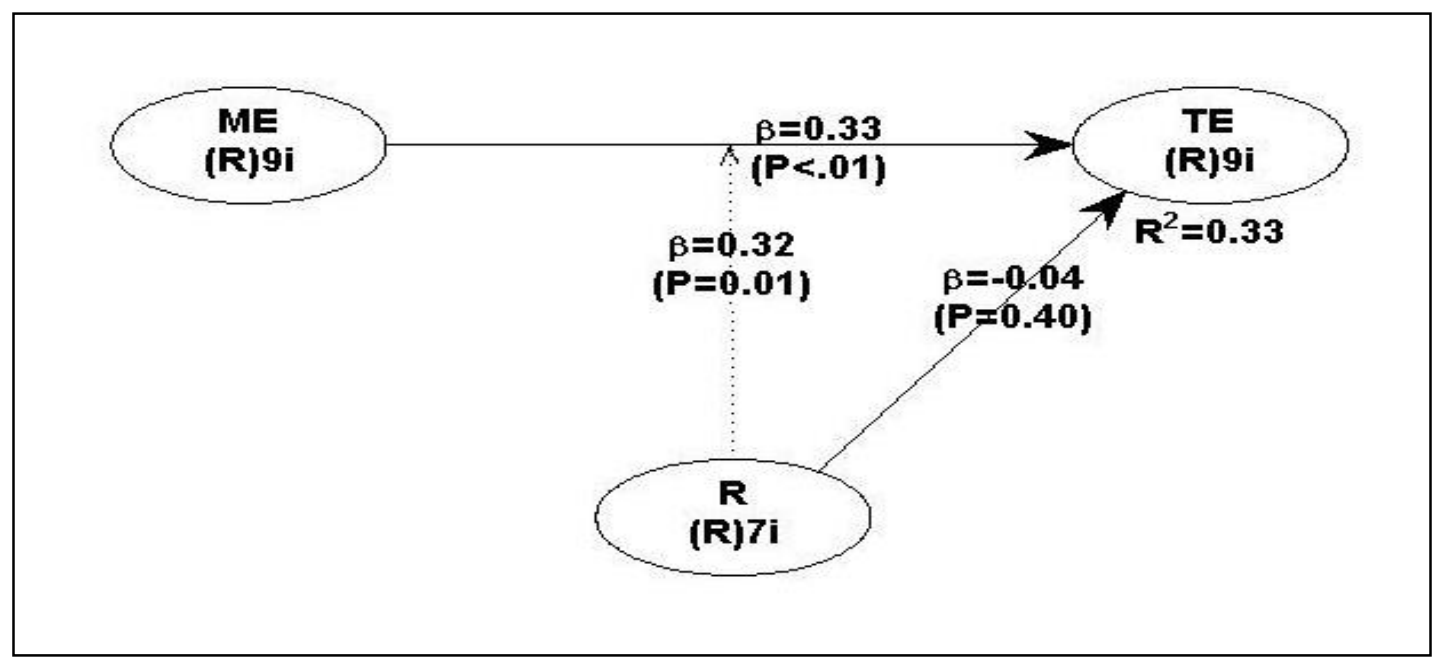

Gambar 1. Hasil Uji Model Struktural Sumber: data primer, diolah (2019)

Tax evasion atau penggelapan pajak memiliki nilai R-square sebesar 0,33. Hal ini berarti bahwa variasi perubahan variabel Tax Evasion dapat dijelaskan oleh variabel Money Ethic dan Variabel Religisuitas sebesar 33 persen, sedangkan 67 persen dijelaskan oleh variabel lain diluar model penelitian. Variabel money ethic mempengaruhi tax evasion atau penggelapan pajak, hal ini dibuktikan dengan nilai signifikansi sebesar $(<0,01)$ yang lebih kecil dari 0,05 . Hal tersebut berarti tax evasion dipengaruhi oleh money ethic atau etika uang, pernyataan tersebut didukung oleh penelitian terdahulu yang dilakukan oleh (Lau, Choe \& Tan, 2013) yang menyatakan bahwa semakin tinggi money ethic sesorang maka individu akan menganggap tindakan penggelapan pajak adalah tindakan yang etis.

Variabel religiusitas memoderasi hubungan antara money ethic atau etika uang dengan tax evasion atau penggelapan pajak. Hal ini dibuktikan dengan nilai signifikansi sebesar $(0,01)$ yang lebih kecil dari 0,05 . Hal tersebut berarti religiusitas sebagai variabel moderasi antara hubungan money ethic dengan tax evasion. Pernyataan ini didukung oleh penelitian sebelumnya yang dilakukan oleh (Lau, Choe \& Tan, 2013) yang menyatakan bahwa religiusitas intrinsik memoderasi hubungan antara etika uang dan penggelapan pajak.

Variabel religiusitas dalam penelitian ini tidak berpengaruh secara langsung terhadap tax evasion atau penggelapan pajak. Hal ini dibuktikan dengan nilai signifikansi sebesar $(0,40)$ yang lebih besar dari 0,05 . Hal tersebut berarti penggelapan pajak tidak dipengaruhi secara langsung oleh religiusitas. Hasil ini didukung oleh penelitian (Basri, 2014); (McKerchar, 2013); (Utama, 2016); (Hidayatulloh, 2016); (Palupi \& Hidayatulloh, 2019) yang mengungkapkan bahwa religiusitas tidak berpengaruh terhadap kepatuhan pajak. Sedangkan (McKerchar, 2013) mengungkapkan lebih lanjut bahwa keyakinan agama memiliki efek yang lemah pada sikap kepatuhan pajak dibandingkan dengan integritas pribadi. 


\section{KESIMPULAN}

Penelitian ini memperoleh hasil bahwa variabel money ethic (etika uang) mempengaruhi tax evasion (penggelapan pajak). Penelitian ini juga membuktikan bahwa hubungan antara etika uang dan penggelapan pajak dimoderasi oleh variabel religiusitas, tetapi dalam penelitian ini variabel tax evasion (penggelapan pajak) tidak dipengaruhi secara langsung oleh variabel religiusitas. Hal tersebut juga membuktikan bahwa variabel religiusitas merupakan variabel moderasi, sehingga dapat disimpulkan bahwa semakin tinggi money ethic seseorang maka semakin tinggi pula potensi dirinya dalam melakukan tax evasion (penggelapan pajak).

Keterbatasan dalam penelitian ini adalah sampel dalam penelitian ini relative sedikit, sehingga dalam penelitian selanjutnya diharapkan untuk memperluas objek penelitian atau memperbanyak sampel penelitian.

\section{DAFTAR PUSTAKA}

Azjen, I. F. M. (1977). a Theoretical Analysis and Review of Empirical Research. Psychological Bulletin, 84(5), 888-918.

Basri, Y. M. (2014). Pengaruh gender, religiusitas dan sikap love of money terhadap persepsi etika penggelapan pajak.

Hafizhah, I. (2016). Pengaruh Etika Uang (Money Ethics) Terhadap Kecurangan Pajak (Tax Evasion) Dengan Religiusitas,Gender dan Materialisme Sebagai Variabel Moderasi. Jurnal Online Mahasiswa (JOM) Bidang Ilmu Ekonomi, 3(1), 1652-1665. Retrieved from https://jom.unri.ac.id/index.php/JOMFEKON/article/view/11770/11418

Hartono, J., \& Abdillah, W. (2014). . Konsep dan Aplikasi (Partial Least Square) untuk Penelitian Empiris (1st ed.). Yogyakarta: BPFE UGM.

Hidayatulloh, A. (2016). Faktor-Faktor Yang Mendorong Wajib Pajak Pribadi Untuk Menggelapkan Pajak. OPTIMUM: Jurnal Ekonomi Dan Pembangunan, 6(2), 189-200.

Hutami, S. (2012). Tax Planning (Tax Avoidance dan Tax Evasion) Dilihat dari Teori Etika. Majalah Online Politeknosains.

Imam, G., \& Latan, H. (2014). (2014). Partial Least Square (PLS) konsep teknik dan aplikasi. Semarang: Universitas Diponegoro Semarang.

Inggit, I. (2019). Kinerja Pajak 2018, Lagi-Lagi Tak Capai Target.

Lau, T. C., Choe, K. L., \& Tan, L. P. (2013). (2013). The Moderating Effect of Religiosity in the Relationship between Money Ethics and Tax Evasion. Asian Social Science, 9(11), 213-220.

Mardiasmo. (2009). Perpajakan.

McDaniel, S.W. and Burnett, J. . (1990). Consumer Religiosity and Retail Store Evaluative Criteria. Journal of the Academy of Marketing Science.

McKerchar, M., Bloomquist, K. and Pope, J. (2013). Indicators of tax morale: an exploratory study. EJournal of Tax Research, Vol. 11 No.

Mehrad, D., \& Mohammadi, S. (2017). Word of Mouth impact on the adoption of mobile banking in Iran. Telematics and Informatics, 34(7), 1351-1363. https://doi.org/10.1016/j.tele.2016.08.009

Nugroho, A. R., \& Masduqi, A. (2014). Application of Partial Least Square Structural Equation Modelling for Assessing the Water Pollution Factor of Kali Aplikasi Partial Least Square Structural Equation Modelling Untuk Menilai Faktor Pencemaran Air Application of Partial Least Square Structur. (April 2018).

Palupi, A. L., \& Hidayatulloh, A. (2019). Studi Kepatuhan Wajib Pajak Orang Pribadi Wirausahawan 
Di Kabupaten Kulon Progo. Jurnal Sistem Informasi, Keuangan, Auditing Dan Perpajakan, 4(1), $58-65$.

Rosianti, C., \& Mangoting, Y. (2014). Pengaruh Money Ethics Terhadap Tax Evasion Dengan Intrinsic Dan Extrinsic Religiosity Sebagai Variabel Moderating. Tax \& Accounting Review, 4(1), 1-11.

Sloan, A. (2002). The Jury's In : Greed Isn't Good.

Tang, T. L. (2002). (n.d.). Is the Love of Money the Root of All Evil? Or Different Strokes for Different Folks: Lessons in 12 Countries. Paper Presented to the International Conference on Business Ethics in the Knowledge Economy. 2002.

Tentama, F., \& . S. (2019). Pengujian Validitas dan Reliabilitas Konstruk pada Organizational Citizenship Behavior. Humanitas, 15(1), 62. https://doi.org/10.26555/humanitas.v15i1.5282

Utama, A. dan D. W. (2016). Pengaruh Religiusitas terhadap Perilaku Kepatuhan Pajak Orang Pribadi di Provinsi DKI Jakarta. Jurnal Lingkar Widyaiswara, Vol 3, No. 